\title{
EDITORIAL
}

\section{Surgical Experimental Neurotherapeutics}

There are many devices currently being used to treat neurological diseases and psychiatric disorders. Although spine instrumentation is more commonly used than any of the devices covered in this issue, we have decided to focus on devices used for neuromodulation due to our personal interests and our belief that such devices are especially suited to experimental neurotherapeutics.

A major advantage of such devices is that their settings can be varied in a range that includes no output or outputs that are not associated with perception by the patient. For many such stimulation therapies, this means that efficacy can be rigorously tested in a randomized double-blind manner. Even spinal cord stimulation (the efficacy of which was thought to be dependent on the patient's experiencing paresthesias in the area or areas affected) has been shown to improve cardiac function at levels that are subthreshold for paresthesias. ${ }^{1}$

Many of these therapies, such as deep brain stimulation (DBS) of the subthalamic nucleus (STN), have been developed from basic science experiments. In addition, much has been learned about the structure and function of the human brain from intraoperative electrophysiologic recording during implantation of these devices. With the ability to vary stimulation parameters, we can learn about the structure and function of various brain nuclei and pathways. The new horizons opened by the development of neuromodulatory techniques and increased understanding of how the nervous system works is what prompted us to become functional neurosurgeons and what is driving the field.

It is indeed an exciting time in this field. ${ }^{2}$ There are well-established therapies, such as DBS for specific movement disorders, ${ }^{3}$ spinal cord stimulation, ${ }^{4}$ intrathecal drug delivery, ${ }^{5}$ sacral nerve stimulation, ${ }^{6}$ and vagal nerve stimulation for epilepsy. ${ }^{7}$ Other therapies have FDA approval but are only now becoming more well known, such as peripheral nerve stimulation. ${ }^{8}$ Auditory brainstem implants are FDA-approved, but - at least for now-only for a very small patient population. ${ }^{9}$ There are expanding indications for use of well-established devices, ${ }^{7,10-12}$ and there are completely new types of devices, like the responsive neurostimulator RNS device by NeuroPace (Mountain View, CA), which is currently under trial. ${ }^{13}$ We have also solicited articles by leaders in the field who are actively developing new ways of delivering electrical stimulation, medications, and gene therapy into the central nervous system. ${ }^{14,15}$ The issue concludes with reviews of ongoing translational research which is at an earlier stage, such as brain-machine interfaces for people who are locked in after stroke, traumatic brain injury, or spinal cord injury. ${ }^{16,17}$

We hope you find the articles selected for this issue to be helpful in assessing the current state of functional neurosurgery. At the rate this field is progressing, this issue presents a snapshot of a rapidly evolving field.

Jason M. Schwalb, M.D. Assistant Professor of Neurological Surgery University of Rochester School of Medicine and

Dentistry

Rochester, NY

Andres M. Lozano, M.D., Ph.D. Senior Scientist

Division of Brain Imaging and Behaviour Systems Neuroscience

Toronto Western Research Institute Toronto Western Hospital Toronto, Ontario, Canada

\section{REFERENCES}

1. Eddicks S, Maier-Hauff K, Schenk M, Müller A, Baumann G, Theres H. Thoracic spinal cord stimulation improves functional status and relieves symptoms in patients with refractory angina pectoris: the first placebo-controlled randomised study. Heart 2007;93:585-590.

2. Schwalb JM, Hamani C. The history and future of deep brain stimulation. Neurotherapeutics 2008;5:3-13.

3. Yu H, Neimat JS. The treatment of movement disorders by deep brain stimulation. Neurotherapeutics 2008;5:26-36.

4. Falowski S, Celii A, Sharan A. Spinal cord stimulation: an update. Neurotherapeutics 2008;5:86-99.

5. Belverud S, Mogilner A, Schulder M. Intrathecal pumps. Neurotherapeutics 2008;5:114-122.

6. Mayer R, Howard F. Sacral nerve stimulation: neuromodulation for voiding dysfunction and pain. Neurotherapeutics 2008;5:107113.

7. Milby AH, Halpern $\mathrm{CH}$, Baltuch GH. Vagus nerve stimulation for epilepsy and depression. Neurotherapeutics 2008;5:75-85.

8. Slavin KV. Peripheral nerve stimulation for neuropathic pain. Neurotherapeutics 2008;5:100-106.

9. Schwartz MS, Otto SR, Shannon RV, Hitselberger WE, Brackmann DE. Auditory brainstem implants. Neurotherapeutics 2008; 5:128-136

10. Arle JE, Shils JL. Motor cortex stimulation for pain and movement disorders. Neurotherapeutics 2008;5:37-49.

11. Larson PS. Deep brain stimulation for psychiatric disorders. Neurotherapeutics 2008;5:50-58.

12. Halpern CH, Samadani U, Litt B, Jaggi JL, Baltuch GH. Deep brain stimulation for epilepsy. Neurotherapeutics 2008;5:59-67. 
13. Sun FT, Morell MJ, Wharen RE. Responsive cortical stimulation for the treatment of epilepsy. Neurotherapeutics 2008;5:68-74.

14. Fiandaca MS, Forsayeth JR, Dickinson PJ, Bankiewicz KS. Image-guided convection-enhanced delivery platform in the treatment of neurological diseases. Neurotherapeutics 2008;5: 123-127.

15. Birdno MJ, Grill WM. Mechanisms of deep brain stimulation in movement disorders as revealed by changes in stimulus frequency. Neurotherapeutics 2008;5:14-26.

16. Giszter S. Spinal cord injury: present and future therapeutics devices and prostheses. Neurotherapeutics 2008;5:147-162.

17. Patil P, Turner D. The development of brain-machine interface neuroprosthetic devices. Neurotherapeutics 2008;5:137146. 